\title{
Relations between problem behaviors, perceived symptom severity and parenting in adolescents and emerging adults with ASD: The mediating role of parental psychological need frustration
}

\author{
Lisa M. Dieleman ${ }^{\mathrm{a}, *}$, Sarah S.W. De Pauw ${ }^{\mathrm{a}, \mathrm{b}}$, Bart Soenens ${ }^{\mathrm{a}}$, Elien Mabbe ${ }^{\mathrm{a}}$, \\ Rachel Campbell ${ }^{\mathrm{a}}$, Peter Prinzie ${ }^{\mathrm{c}}$ \\ a Ghent University, Department of Developmental, Personality and Social Psychology, H. Dunantlaan 2, 9000 Ghent, Belgium \\ ${ }^{\mathrm{b}}$ Ghent University, Department of Special Needs Education, H. Dunantlaan 2, 9000 Ghent, Belgium \\ ${ }^{\mathrm{c}}$ Erasmus University Rotterdam, Faculty of Social Sciences, Department of Psychology, Education \& Child Studies, Burg. Oudlaan 50, 3000 DR \\ Rotterdam, The Netherlands
}

\section{A R T I C L E I N F O}

Number of reviews completed is 2 .

Keywords:

Autism spectrum disorder

Self-determination theory

Child maladjustment

Parenting behavior

Psychological need frustration

\begin{abstract}
A B S T R A C T
Research in parents of youngsters with Autism Spectrum Disorder (ASD) increasingly documents associations between children's problem behaviors and symptom severity and more dysfunctional and less adaptive parenting behaviors. However, the mechanisms underlying these associations have not been examined thoroughly. This study examines the mediating role of parental need frustration in the relation between child maladjustment (i.e., problem behavior and autism severity) and parenting behavior (i.e., controlling and autonomy-supportive parenting). The sample included 95 parents of adolescents/emerging adults with ASD ( $M_{\text {age }}=18.8$ years, $S D=2.3$ ). Parents completed questionnaires assessing their parenting strategies and psychological need frustration as well as the internalizing and externalizing problem behaviors and autism severity of their child. Results indicate that the association between externalizing problems and controlling parenting was partially mediated by need frustration. This suggests that externalizing problems go together with lower feelings of parent-child closeness, lower parental competence, and a decreased sense of volitional functioning, feelings that, in turn, relate to more controlling strategies. Symptom severity has a direct negative association with autonomy support, suggesting that parents lower their autonomy support when their child has high levels of autism symptoms, without experiencing these symptoms as a threat to their own psychological needs.
\end{abstract}

\section{What this paper adds?}

This study aims to address gaps in the literature on the associations between child maladjustment and parenting in a late adolescent ASD population by examining the intervening role of parental need frustration, as conceptualized in Self-Determination Theory (Deci \& Ryan, 2000). The results indicate that only externalizing problem behaviors of adolescents and emerging adults with ASD relate to more controlling parenting, partially via the frustration of parents' need for autonomy, relatedness, and competence. Perceived autism symptoms, however, relate directly to less autonomy supportive parenting. In addition to yielding more insight into the associations between child maladjustment and parenting in this age period, these findings identify parents' own experiences of need frustration as a valuable focus of intervention in the guidance of parents rearing late adolescents with ASD.

\footnotetext{
* Corresponding author.

E-mail address: Lisa.Dieleman@UGent.be (L.M. Dieleman).
} 


\section{Introduction}

Ample research has shown that parenting a child with an Autism Spectrum Disorder (ASD) is a unique and challenging experience, increasing the risk for parental stress and reduced well-being (Hayes \& Watson, 2013). Even though most studies to date have focused on early and middle childhood, this also appears to be true in late adolescence and young adulthood (Taylor \& Seltzer, 2011). Two factors that have consistently been associated with parental distress in parents of children with ASD are (1) the co-occurring behavioral problems that children with ASD often exhibit, such as disruptive behavior (Osborne \& Reed, 2009) and (2) the autism symptom severity (i.e., impairments in social communication and interaction, and restricted patterns of behavior) (Seltzer, Krauss, Orsmond, \& Vestal, 2001). In addition to their impact on parents' well-being, these problem behaviors and symptoms also relate to parenting behavior (Greenberg, Seltzer, Hong, \& Orsmond, 2006). Less is known, however, about the processes involved in these associations between child maladjustment (i.e., ASD symptoms and problem behaviors) and parenting behavior. Herein, we propose on the basis of Self-Determination Theory (SDT, Deci \& Ryan, 2000) that frustration of parents' psychological needs may play an important explanatory role in these associations.

\subsection{Parenting a child with ASD: the impact of specific child characteristics}

Several studies in ASD populations, spanning diverse age groups, have shown longitudinal associations between children's problem behaviors and parenting behavior. Taylor and Seltzer (2011) found, for instance, that changes in maladaptive behaviors of adolescents with ASD were related to changes in maternal warmth: when adolescents exhibit high levels of maladaptive behaviors, mothers express less warmth over time. In a 9-year longitudinal study, Dieleman, De Pauw, Soenens, Beyers, and Prinzie (2017) documented that externalizing child problems at the age of 10 were predictive of parental control (i.e. discipline and harsh punishment) six years later. However, this study also reported a more adaptive association: externalizing problems at the age of 16 predicted more positive parenting behavior three years later. Greenberg et al. (2006) also showed a more adaptive association between problem behavior and parenting in parents of adolescents and adults with ASD. Specifically, internalizing problems predicted a decrease in expressed negative emotion (i.e., criticism and/or emotional over-involvement) 18 months later (Greenberg et al., 2006).

In addition, there is mounting evidence that autism symptoms also relate to parents' behaviors. Smith, Greenberg, Seltzer, and Hong (2008), for instance, found that autism severity was predictive of decreased maternal praise in parents of adolescents and adults with ASD 18 months later. The severity of autism symptoms is also related to less emotional closeness between parent and child (Hoffman, Sweeney, Hodge, Lopez-Wagner, \& Looney, 2009) and to lower quality parent-child interactions (Hobson, Tarver, Beurkens, \& Hobson, 2016). Beurkens, Hobson, and Hobson (2013) concluded that the severity of autism symptoms impacts on parent-child interactions by undermining the communication, coordination, and responsivity between parent and child.

Taken together, there is a growing literature indicating that both children's problem behaviors and autism severity are potential determinants of parenting behavior in ASD. These studies also suggest that these child characteristics relate to parenting not only during early childhood, but continue to shape parenting behavior throughout adolescence and adulthood (Dieleman et al., 2017; Taylor \& Seltzer, 2011). Given that the transition into adulthood constitutes a challenging period for both parents and youngsters with ASD (Taylor \& Seltzer, 2010) and that parents still play an important, yet changing, role during this transition (Nelson, PadillaWalker, Christensen, Evans, \& Carroll, 2011), it is imperative to examine whether and why problem behavior and autism severity are related to parenting during this developmental period.

Although the relations between child maladjustment (i.e., problem behaviors and ASD symptoms) and parenting behavior are well-documented, few studies have looked at the underlying mechanisms of these associations. The aim of the present study was to address this gap by examining whether parents' experiences of psychological need frustration, as asserted by the psychological framework of SDT (Deci \& Ryan, 2000), represent an underlying mechanism behind these associations.

\subsection{Mechanisms behind effects of ASD symptoms and problem behaviors on parenting}

Self-Determination Theory (SDT) is a broad psychological theory on human development (Deci \& Ryan, 2000) which is applied increasingly in research on parenting in general and in specific populations (Gilmore, Cuskelly, Jobling, \& Hayes, 2009). Central to SDT is the assumption that people have an inherent need for autonomy, relatedness, and competence (Deci \& Ryan, 2000). These needs are considered as fundamental nutriments for individuals' well-being as well as for the quality of their social interactions. The need for autonomy involves experiencing psychological freedom and a sense of authenticity. When this need is frustrated, people feel pressured to engage in behaviors against their will. The need for relatedness entails feelings of interpersonal warmth and reciprocal care. Frustration of this need manifests in experiences of social isolation and rejection. The need for competence refers to feelings of being effective or skilled in the activities people undertake or in the goals they aim to accomplish. Frustration of this need manifests in feelings of failure and inferiority. While the satisfaction of these three needs is considered essential for optimal development and well-being, the frustration of these needs is said to jeopardize development and to increase the risk for maladjustment and ill-being (Deci \& Ryan, 2000).

\subsubsection{Need-supportive versus need-thwarting parenting behavior}

Within SDT, parenting behavior is considered an important source of children's need satisfaction or frustration. Need-supportive parenting refers to parenting behaviors that satisfy children's need for autonomy, relatedness, and competence, whereas need- 
thwarting parenting refers to parenting behaviors that impede children's psychological needs. One important component of needsupportive parenting is autonomy-supportive parenting (Joussemet, Landry, \& Koestner, 2008). Autonomy-supportive parenting refers to parents' promotion of their child's volitional and self-initiating functioning, for instance, by offering choice, by recognizing the child's perspective, and by giving a meaningful rationale for requests (Joussemet et al., 2008). In contrast to autonomy-supportive parenting, controlling parenting thwarts children's needs by ignoring the child's perspective and by pressuring children to think, feel or act in specific ways (Soenens \& Vansteenkiste, 2010). Parents can use external or internal pressure in order to impose their own perspective on their child. Over-reactive discipline is a type of externally controlling parenting which refers to the parental tendency to respond in a hostile and impatient way (Prinzie, Onghena, \& Hellinckx, 2007). Psychological control is a type of internally controlling parenting which refers to the use of insidious techniques to pressure a child, such as guilt-induction or love withdrawal (Soenens \& Vansteenkiste, 2010).

Research in typical populations has convincingly shown that autonomy-supportive parenting contributes to the well-being and adjustment of children, whereas controlling parenting is a robust predictor of maladjustment (Joussemet et al., 2008). Although studies examining these parenting behaviors in ASD populations are scarce, some findings do indicate that controlling and autonomysuppressing parenting behavior impede the development of youngsters with ASD (Dieleman et al., 2017; Greenberg et al., 2006). To date, very few studies focused on the role of autonomy support in the ASD population. Yet, a few studies in the educational domain suggest that autonomy support is beneficial for youth with ASD (Reutebuch, El Zein, \& Roberts, 2015; Shea, Millea, \& Diehl, 2013).

\subsubsection{Parents' psychological needs}

The processes of need-satisfaction and -frustration are not only essential mechanisms in children's development, but they are also key determinants of parenting behavior (Grolnick, 2003). When parents experience need-satisfaction, they have sufficient energy to engage in positive parenting behaviors such as autonomy-supportive behavior (Mabbe, Soenens, Vansteenkiste, Van der KaapDeeder, \& Mouratidis, in press). In contrast, parents who experience need-frustration respond in more defensive ways, which increases the likelihood to engage in less adaptive parenting behaviors, such as psychological control or over-reactive discipline (Mabbe et al., in press).

In turn, parental need experiences are determined by multiple factors, including parents' personality, social-contextual influences, and child characteristics. One factor that has been identified as a powerful source of influence on parents' needs is child problem behavior, and aggressive behavior in particular (Grolnick, Gurland, DeCourcey, \& Jacob, 2002). When confronted with problem behavior, parents are likely to feel more alienated from the child (relatedness frustration), incapable of regulating the child's behavior (competence frustration), and pressured to deal with undesired behavior (autonomy frustration). These experiences of need frustration can then translate into more controlling and autonomy-suppressing behaviors. Consistent with this hypothesis, de Haan, Soenens, Dekovic, and Prinzie (2013) found, in a longitudinal study with a population-based sample, that childhood aggression was negatively related with parents' need satisfaction six years later. In turn, low need satisfaction was related to more frequent parental engagement in psychologically controlling and over-reactive practices towards their child.

Taken together, previous research grounded in SDT suggests that parental experiences of need frustration are likely to play an intervening role in the association between child maladjustment and parenting behavior. Parents' psychological needs have not yet been examined in parents of adolescents or emerging adults with ASD. This is unfortunate because the problem behaviors and symptoms displayed by adolescents/emerging adults with ASD can potentially undermine parents' needs (Rodrigue, Morgan, \& Geffken, 1990). For example, when an adolescent with ASD exhibits disruptive behavior, parents might feel forced to avoid certain activities (i.e., need for autonomy), feel unsure about the best way to deal with this behavior (i.e., need for competence), and feel less connected with their child (i.e., need for relatedness), which makes them more likely to react in a controlling way and less likely to be autonomy supportive.

\subsection{Aims and hypotheses}

The aim of this study was to examine the explanatory role of parental need frustration in the association between child maladjustment (i.e., internalizing and externalizing problem behavior and symptom severity) and parenting behavior (i.e., autonomy support and controlling parenting) in parents of adolescents and emerging adults with ASD. First, we examined the relation between problem behavior, symptom severity and parenting behaviors. We hypothesized that problem behavior and symptom severity would relate positively to controlling parenting (i.e., psychological control and over-reactive discipline) and negatively to autonomy supportive parenting. We expected the relations between externalizing problems and parenting to be most pronounced. Second, we examined whether parents' psychological need frustration would mediate the relations between child maladjustment and parenting behavior. We expected problem behavior and symptom severity to relate positively to parents' need frustration. In turn, we expected need frustration to relate positively and negatively to controlling and autonomy-supportive parenting, respectively.

\section{Method}

\subsection{Procedure and participants}

The current study is part of a broader three-wave longitudinal study on parenting in children with ASD (see Dieleman et al., 2017). The current study focuses on findings from the 3rd wave of data collection (conducted in 2015). This 3rd wave is a follow-up to data collected in 2005 (Wave 1) and 2012 (Wave 2). At the start of the study (Wave 1) parents of children with ASD were invited to 
Table 1

Demographic information $(\mathrm{n}=95)$.

\begin{tabular}{ll} 
& $n$ \\
\hline Nationality parents (mother/father) & \\
Belgian & $85 / 85$ \\
Other European nationality & $8 / 6$ \\
Unknown & $2 / 4$ \\
Education level parents (mothers/fathers) & \\
Primary school & $1 / 5$ \\
Secondary school & $40 / 40$ \\
Higher education (college or university) & $51 / 41$ \\
Unknown & $3 / 9$ \\
Comorbid diagnosis adolescent/emerging adult ${ }^{\mathrm{a}}$ & 53 \\
Type of education adolescent/emerging adult & \\
Regular secondary education & 31 \\
Special secondary education & 24 \\
Higher education & 15 \\
Other types of education & 4 \\
Employed & 14 \\
Unknown/Other ${ }^{\mathrm{b}}$ & 7 \\
Living situation adolescent/emerging adult & 3 \\
At home with parent(s) & 3 \\
During the week at boarding school, in the weekend at home & 3 \\
During the week in dorms, in the weekend at home & 3 \\
Living independently & 2 \\
Living in an institution & 3 \\
\hline Other & \\
\hline
\end{tabular}

${ }^{a}$ Reported by parents. Includes comorbidity with $\mathrm{AD}(\mathrm{H}) \mathrm{D}$, Specific Learning Disorders, Motor disabilities, etc. Excludes intellectual disability (IQ < 70). Parents could indicate more than one comorbidity.

${ }^{\mathrm{b}}$ Includes unemployed adolescents, adolescents in day care, etc.

participate (1) through the registries of autism-services centers, (2) by placing announcements on websites regarding ASD, and (3) by contacting practitioners. The diagnostic status of the children was established through written parent-report and was verbally confirmed to a research assistant. Only parents of children (1) with a formal diagnosis of Autistic Disorder, Asperger's Syndrome or Pervasive Developmental Disorder-Not Otherwise Specified (PDD-NOS) based on DSM-IV-TR or ICD-10 criteria and (2) who had a Tscore above 60 (i.e., cut-off for a mild to moderate range of ASD symptoms) on the Social Responsiveness Scale (SRS) (Constantino \& Gruber, 2005; Roeyers, Thys, Druart, De Schryver, \& Schittekatte, 2011) were allowed to participate.

Originally, 116 parents participated at the 3rd wave of data collection, but only 95 children had a T-score above 60 on the SRS. Therefore, the total sample at wave 3 included 95 parents, mainly mothers (96\%) of adolescents and emerging adults with ASD (72 boys, 23 girls). Mothers were 48.4 years $(S D=4.6)$ old on average, fathers were 51.0 years $(S D=5.3)$ old on average, and the adolescents/emerging adults were 18.8 years old $(S D=2.3$, range $=14-24)$ on average at the 3rd wave of data collection. Written informed consent was obtained from all participants. Additional demographic information is summarized in Table 1.

\subsection{Instruments}

\subsubsection{Problem behavior}

Parents rated their child's behavioral problems on the Child Behavior Checklist/6-18 (CBCL; Achenbach \& Rescorla, 2001). The CBCL is a parent-report questionnaire assessing problem behavior, over the past six months, on a 3-point Likert scale ranging from (0) not true to (2) very true. Previous research identified the CBCL to be adequate for examining problem behavior in adolescents and emerging adults (18-25 years) with ASD (Holtmann, Bolte, \& Poustka, 2007). The subscales aggressive behavior (18 items, e.g., "Destroys his/her own things") and rule-breaking (17 items, e.g., "Breaks rules at home, school, or elsewhere") represented the externalizing problems of the child. Internalizing problems were represented by the subscales anxious/depressive behavior (13 items, e.g., "Fears certain animals, situations, or places, other than school"), withdrawn/depressive behavior (8 items, e.g., "Unhappy, sad, or depressed"), and somatic complaints (11 items, e.g., "Overtired without good reason"). Cronbach's alpha of the subscales ranged between 0.81 (for somatic complaints) and 0.91 (for aggressive behavior).

\subsubsection{Autism severity}

Autism severity, as perceived by parents, was assessed with the Social Responsiveness Scale (SRS) (Constantino \& Gruber, 2005; Roeyers et al., 2011). This parent-report questionnaire assesses ASD symptoms that the child displayed over the past six months, based upon the social impairments, social awareness, social information processing, capacity for reciprocal social communication, social anxiety/avoidance, and autistic preoccupations s/he exhibited (e.g., "My child prefers to be alone rather than with others"). 
This 65-item measure is rated on a 4-point Likert scale ranging from (1) not true to (4) almost always true. Cronbach's alpha of the questionnaire was 0.93 .

\subsubsection{Parental psychological need frustration}

In order to evaluate experiences of need frustration, we follow de Haan et al. (2013) and included three subscales of the Parenting Stress Index (PSI, Abidin, 1990; de Brock, Vermulst, Gerris, \& Abidin, 1992) that show conceptual strong links with the three basic needs postulated by SDT. The Role-Restriction scale measures the extent to which parents feel constrained by their responsibilities as a parent (7 items, e.g., "I often feel that my child's needs and wishes control my life") and was used as an indicator of autonomy frustration. The Attachment scale measures parents' lack of a sense of closeness with their child (6 items, e.g., "I am bothered that I feel less close and affectionate towards my child than I expected") and was used as an indicator of relatedness frustration. The Sense of Competence scale measures the extent to which parents feel incapable in dealing with the parental tasks (13 items, e.g., "I feel that I am not very good at being a parent") and was used as an indicator of competence frustration. Items were scored on a 5-point Likert scale ranging from 'Totally not agree' to 'Totally agree'. Higher scale scores reflected more need frustration. The PSI is a well-validated instrument across typical and atypical development (for ASD, see Hoffman et al., 2009). Cronbach's alpha of the scales for rolerestriction, attachment, and sense of competence scale was respectively $0.83,0.58$ and 0.84 . Cronbach alpha of the total score (i.e., composite of the three subscales) was 0.83 .

\subsubsection{Parenting}

In line with SDT-based research on parenting in typically developing samples, we administered one questionnaire describing an autonomy-supportive rearing environment and two tapping into a more controlling environment (i.e., over-reactive discipline and psychological control). All items were scored on a 5-point Likert scale going from 'totally disagree' to 'fully agree'.

Autonomy support was measured using the Autonomy Support Scale of the Perceptions of Parents Scale (POPS; Grolnick, Ryan, \& Deci, 1991). This scale assesses the degree to which parents support children's volitional functioning by offering choice, supporting exploration, and trying to understand the child's point of view (e.g., "I am usually willing to consider things from my child's point of view"). Only the five items that directly measured autonomy-support were included and reversed items were removed. Cronbach's alpha of this scale was 0.68 .

Over-reactive discipline was assessed using the Over-reactivity scale of the Parenting Scale (Arnold, O'Leary, Wolff, \& Acker, 1993; Prinzie et al., 2007). This scale measures the extent to which parents respond with irritation, anger, frustration, or impatience towards their child. In the current study, we selected five items from the original scale (e.g., "When my child misbehaves, I am so frustrated or angry that he/she notices it"). Cronbach's alpha of this scale was 0.71 .

Psychological control was assessed with the parent version (Soenens, Vansteenkiste, Luyckx, \& Goossens, 2006) of the Psychological Control Scale (PCS; Barber, 1996). The eight-item scale measures several aspects of psychologically controlling parenting: constraining verbal expressions, personal attack, love withdrawal, and invalidating feelings (e.g., "I tend to be less friendly to my son/daughter if he/she does not see things like I do"). Cronbach's alpha of this scale was 0.76.

\subsection{Statistical analyses}

First, we examined descriptive statistics, correlations, and the role of background variables. Second, the relation between child maladjustment, parenting and parental need frustration were examined using structural equation models (SEM) with latent variables using Mplus7.3 (Muthén \& Muthén, 1998-2012). Little's missing completely at random (MCAR) test produced ratio of chi-square/ degrees of freedom $\left(\chi^{2} / \mathrm{DF}\right)$ of 1.57 , which indicates that the data were likely MCAR (Bollen, 1989). Therefore, full information maximum likelihood (FIML) was used when testing the structural equation models.

The intervening role of need frustration was tested by combining (1) model comparisons and (2) testing of indirect effects. As for the model comparisons, we followed Holmbeck's guidelines (1997) by first testing a model which only includes direct paths between the independent variables and the dependent variables. Next, we test a full mediation model by only including indirect paths via the mediator. Finally, we test a partial mediation model by adding the direct paths between the independent variables and the dependent variables back in. Full mediation is shown when the fit of the partial mediation is not significantly better than the fit of the full mediation model (Holmbeck, 1997). As for the testing of indirect effects, we used bootstrapping (using 1000 samples) to account for potential deviations from multivariate normality (Preacher \& Hayes, 2008). Model fit was evaluated with the ratio of chi-square/ degrees of freedom $\left(\chi^{2} / \mathrm{DF}\right)$, comparative fit index (CFI), root mean square error of approximation (RMSEA), and standardized root mean square residual (SRMR). A good model fit is indicated by as $\chi^{2} / \mathrm{DF}$ around 2 or lower, a CFI value of 0.95 or higher, a RMSEA value of 0.08 and a SRMR value of 0.08 or lower (Hu \& Bentler, 1999; Kline, 2010).

\section{Results}

\subsection{Preliminary analyses}

Table 2 presents the means, standard deviations and correlations among the main study variables. Prior to examining the associations between the child maladjustment and parenting, the relation between demographic characteristics, such as proband age and gender, and parental age and education, and the study variables was examined. Probands' and mothers' age were not significantly related with any of the study variables (Table 2). To explore the role of probands' gender, we evaluated group differences 
Table 2

Descriptive Statistics, Reliability, and Correlations of Perceived Symptom Severity, Problem Behavior, Parental Need Frustration, and Parenting Behaviors ( $\mathrm{n}=$ 95).

\begin{tabular}{|c|c|c|c|c|c|c|c|c|c|c|c|c|c|c|c|}
\hline & $\alpha$ & $M$ & $S D$ & 1 & 2 & 3 & 4 & 5 & 6 & 7 & 8 & 9 & 10 & 11 & 12 \\
\hline Age proband & & 18.77 & 2.30 & -0.11 & -0.12 & -0.12 & -0.09 & -0.05 & -0.06 & -0.02 & -0.01 & 0.03 & -0.02 & -0.02 & 0.09 \\
\hline Age Mother & & 48.38 & 4.62 & 0.08 & 0.04 & 0.09 & -0.06 & 0.07 & -0.04 & -0.06 & 0.02 & 0.03 & 0.02 & 0.04 & -0.08 \\
\hline $\begin{array}{l}\text { 1. Perceived symptom } \\
\text { severity }\end{array}$ & 0.93 & 82.82 & 25.38 & & & & & & & & & & & & \\
\hline 2. Aggressive behavior & 0.91 & 5.87 & 6.28 & $0.35^{\text {** }}$ & & & & & & & & & & & \\
\hline 3. Rule-breaking & 0.84 & 2.31 & 3.73 & $0.32^{* * *}$ & $0.79^{3 * k \times k}$ & & & & & & & & & & \\
\hline $\begin{array}{l}\text { 4. Anxious/depressive } \\
\text { behavior }\end{array}$ & 0.89 & 6.54 & 5.58 & $0.35^{k * *}$ & 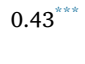 & $0.22^{*}$ & & & & & & & & & \\
\hline $\begin{array}{l}\text { 5. Withdrawn/ } \\
\text { depressive behavior }\end{array}$ & 0.78 & 4.61 & 3.52 & $0.50^{\text {sex.x }}$ & 0.19 & 0.18 & $0.53^{k \text { knth }}$ & & & & & & & & \\
\hline 6. Somatic complaints & 0.81 & 3.08 & 3.60 & $0.28^{* * *}$ & $0.28^{\text {k*k }}$ & 0.18 & $0.69^{* * *}$ & $0.38^{* x * x}$ & & & & & & & \\
\hline $\begin{array}{l}\text { 7. Competence } \\
\text { frustration }\end{array}$ & 0.84 & 2.22 & 0.78 & 0.10 & 0.20 & 0.13 & 0.11 & 0.18 & 0.05 & & & & & & \\
\hline $\begin{array}{l}\text { 8. Relatedness } \\
\text { frustration }\end{array}$ & 0.58 & 1.71 & 0.58 & 0.17 & 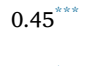 & $0.32^{\text {k** }}$ & $0.21^{*}$ & $0.21^{*}$ & 0.12 & 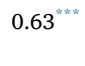 & & & & & \\
\hline 9. Autonomy frustration & 0.83 & 2.51 & 0.94 & $0.44^{k * * * x}$ & $0.26^{*}$ & 0.14 & 0.09 & $0.29^{\text {** }}$ & 0.07 & $0.55^{k \times 2 \times k}$ & $0.44^{* * 2 * k}$ & & & & \\
\hline $\begin{array}{l}\text { 10. Overreactive } \\
\text { Discipline }\end{array}$ & 0.71 & 2.56 & 0.73 & 0.12 & $0.42^{x+k x}$ & $0.27^{\text {k* }}$ & 0.20 & 0.13 & 0.10 & $0.49^{\text {sinde }}$ & $0.48^{\text {thesck }}$ & $0.36^{\text {*ase }}$ & & & \\
\hline $\begin{array}{l}\text { 11. Psychological } \\
\text { control }\end{array}$ & 0.76 & 1.99 & 0.56 & 0.09 & $0.39^{* * * *}$ & $0.30^{\text {k** }}$ & 0.06 & 0.07 & -0.07 & $0.52^{\text {*x+ket }}$ & $0.50^{\text {**xkr }}$ & $0.35^{\text {*3kek }}$ & $0.67^{* * \times k x}$ & & \\
\hline 12. Autonomy support & 0.68 & 4.01 & 0.60 & $-0.28^{* k *}$ & -0.08 & -0.03 & 0.10 & 0.05 & 0.08 & -0.16 & -0.18 & -0.19 & -0.15 & -0.13 & \\
\hline
\end{tabular}

$$
\begin{aligned}
& * p<0.05 \\
& * * p<0.01 \\
& * * * p<0.001
\end{aligned}
$$

using Analyses of Variance. There were significant differences between boys and girls concerning their internalizing problem behaviors $(F(1,88)=14.91, p<0.001$ for anxious/depressive behavior, $F(1,92)=6.74, p<0.05$ for withdrawn/depressive behavior, and $F(1,91)=7.77, p<0.01$ somatic complaints), with girls exhibiting significantly more anxious/depressive behavior $\left(M_{\text {girl }}=10.27\right.$ (6.53), $M_{\text {boy }}=5.37$ (4.71)), withdrawn/depressive behavior $\left(M_{\text {girl }}=6.22\right.$ (3.69), $M_{\text {boy }}=4.08$ (3.34)), and somatic complaints $\left(M_{\text {girl }}=4.83\right.$ (4.79), $M_{\text {boy }}=2.50(2.93)$ ). The Kruskal-Wallis test indicated that parental level of education was not related to the variables of interest.

\subsection{Primary analyses}

Prior to estimating the structural models, we examined a measurement model with latent factors for externalizing problems, symptom severity, need frustration, controlling parenting and autonomy support. Internalizing problems were not included in the models as no associations were found between internalizing and parenting in this sample (see Table 2). The latent factor for externalizing problem behaviors was represented by the subscales for aggressive and rule-breaking behavior. In line with previous studies in typical samples, we combined the subscales for autonomy, relatedness and competence frustration into a latent factor for need frustration (Bartholomew, Ntoumanis, Ryan, Bosch, \& Thogersen-Ntoumani, 2011). Controlling parenting behavior was represented by the subscales psychological control and over-reactive discipline. The latent factors for both perceived symptom severity and autonomy support were represented by three and two parcels, respectively, which were created through random selection of items. Using parcels has been put forward as a suitable technique for creating latent factors from unidimensional scales (Little, Cunningham, Shahar, \& Widaman, 2002). The measurement model yielded an acceptable fit, $\chi^{2} / \mathrm{DF}=1.59$, CFI $=0.96$, RMSEA $=0.08$, SRMR $=0.07$. Next, the latent factor scores of this measurement model were saved and used for further analyses. We used this approach to increase the ratio of the sample size to the number of parameters, thereby still controlling for the measurement errors.

A direct effect model was tested by including only paths from externalizing problems and symptom severity to the parenting behaviors, which were allowed to correlate. This fully saturated model (which, by definition, had perfect fit) indicated that externalizing problems related positively to controlling parenting $(\beta=0.59 ; p<0.001)$, whereas symptom severity related negatively to autonomy support $(\beta=-0.27 ; p<0.001)$. The relations between externalizing problems and autonomy support $(\beta=-0.01$; $n s)$, and between symptom severity and controlling parenting $(\beta=-0.08 ; n s)$ were not significant.

Next, we tested a full mediation model by introducing need frustration into the model as an intervening variable and by only including indirect paths from the independent variables to the parenting behaviors through need frustration. This model $\left(\chi^{2} /\right.$ $\mathrm{DF}=7.23$, CFI $=0.87$, RMSEA $=0.26$, SRMR $=0.06$ ) showed that externalizing problems were positively associated with need frustration $(\beta=0.45 ; p<0.001)$, whereas symptom severity was unrelated to need frustration $(\beta=0.16 ; n s)$. Need frustration was related positively to controlling parenting $(\beta=0.85 ; p<0.001)$ and negatively with autonomy support $(\beta=-0.32 ; p<0.001)$. The indirect associations (tested with bootstrapping) between externalizing problems and controlling parenting $(\beta=0.38$; $95 \% \mathrm{CI}=$ [0.23;.54]; $p<0.001)$ and autonomy support $(\beta=-0.14 ; 95 \% \mathrm{CI}=[-0.25 ;-0.04] ; p<0.01)$ via need frustration were significant. 


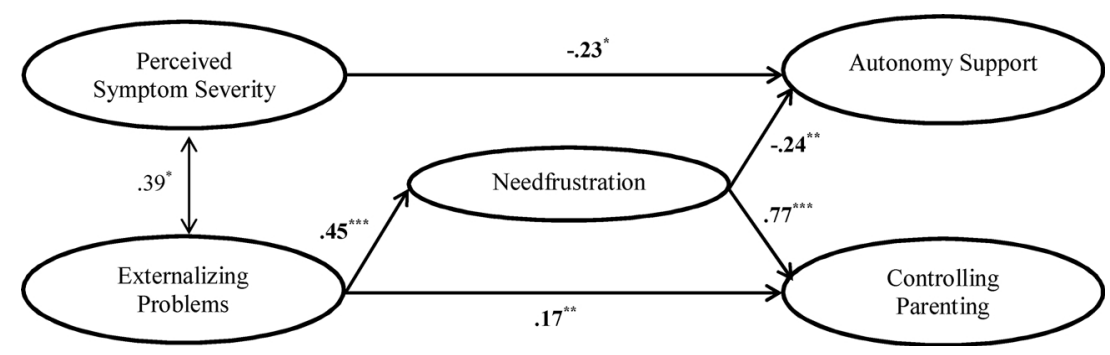

Fig. 1. Final structural model of associations between externalizing problems, perceived symptom severity, need frustration, and parenting behavior. Note: ${ }^{*} p<0.05,{ }^{* * *} p<0.01,{ }^{* * * *} p<0.001$, only significant relations are shown. Coefficients shown are standardized coefficients.

Finally, we tested a partial mediation model in which direct paths between externalizing problems and controlling parenting and between symptom severity and autonomy support were added back to the model. This model $\left(\chi^{2} / \mathrm{DF}=8.69\right.$, CFI $=0.92$, RMSEA $=0.29$, SRMR $=0.05)$ had a significantly better fit than the full mediation model $\left(\chi^{2} \Delta(2)=11.56, p<0.01\right)$ and showed that symptom severity continued to yield a direct negative association with autonomy support $(\beta=-0.23 ; p<0.05)$. Externalizing problems were related to controlling parenting both directly $(\beta=0.17 ; p<0.01)$ and indirectly via need frustration (indirect effect tested with bootstrapping: $\beta=0.34 ; 95 \% \mathrm{CI}=[0.21 ; .47] ; p<0.001)$. Moreover, externalizing problems related indirectly to autonomy support via need frustration $(\beta=-0.11 ; 95 \% \mathrm{CI}=[-0.20 ;-0.02] ; p<0.05)$. Symptom severity was unrelated to need frustration $(\beta=0.16 ; n s)$. This partial mediation model is presented in Fig. 1 and explained 75\% of controlling parenting and 15\% of autonomy supportive parenting.

Although the partial mediation model fitted the data better than the full mediation model, some of the fit indices (RMSEA in particular) still indicated suboptimal fit. An exploration of the modification indices indicated that adding a path from symptom severity to controlling parenting would improve the fit of this model considerably $\left(\chi^{2} / \mathrm{DF}=1.16, \mathrm{CFI}=1.00\right.$, RMSEA $=0.06$, SRMR = 0.02). This additional path indicated a negative association between symptom severity and controlling parenting $(\beta=-0.22 ; p<0.001)$. Because this negative association was not present in the direct effect model, nor in the correlational analyses (Table 2), and because there is a very high association between need frustration and controlling parenting, this association can be interpreted as a suppression effect (Kline, 2010). Therefore, this association was not retained in the final model and will not be interpreted as a substantive finding.

\subsection{Supplementary analyses}

One of the limitations of this model is its cross-sectional nature. As the study was part of a broader, longitudinal study, it was possible to control for symptom severity and behavioral problems as reported three years earlier (Wave 2). This allowed us to examine whether changes in autism symptoms and behavioral problems would relate to parents' need frustration and parenting behavior. Because not all parents participating in wave 3 had previously also participated in the 2nd wave of data-collection, these supplementary analyses only include a subsample of the participants $(n=60)$. Cronbach's alpha of the CBCL subscales administered at wave 2 ranged between 0.72 (for aggressive behavior) and 0.89 (for rule-breaking behavior). Cronbach's alpha of the SRS administered at wave 2 was 0.94 .

These analyses revealed primarily that there is a strong stability in both externalizing problems and symptom severity across three years (respectively $\beta=0.92 ; p<0.001$ and $\beta=0.82 ; p<0.001$ ). Noteworthy, all significant paths between current externalizing problems, symptom severity, need frustration and parenting behavior remained significant when controlling for previously reported externalizing problems and symptom severity. More specifically, the change in externalizing problems and symptom severity related significantly with respectively controlling $(\beta=0.18 ; p<0.01)$ and autonomy supportive parenting $(\beta=-0.22 ; p<0.05)$. The change in externalizing problems is also indirectly related to controlling and autonomy supportive parenting through need frustration (respectively $\beta=0.42 ; 95 \% \mathrm{CI}=[0.32 ; .51] ; p<0.001$ and $\beta=-0.14 ; 95 \% \mathrm{CI}=[-0.25 ;-0.02] ; p<0.05$ ).

\section{Discussion}

Research is increasingly documenting the role of children's problem behaviors and symptom severity in parenting behaviors in the context of ASD (Smith et al., 2008). The underlying mechanisms of these effects, however, have not been examined thoroughly. This study aimed to address this gap by examining the mediating role of parental need frustration in the relation between child maladjustment and parenting behavior of youth with ASD during late adolescence/emerging adulthood. Based on SDT (Deci \& Ryan, 2000), we hypothesized that all three indicators of maladjustment (i.e., internalizing problems, externalizing problems, and symptom severity) would relate to the frustration of parents' psychological needs which, in turn, related to controlling parenting and autonomy support.

Findings showed that the probands' externalizing problems were most strongly, and even uniquely, related to parents' use of controlling techniques (i.e., psychological control and over-reactivity). Supplementary analyses further showed that not only concurrent levels of externalizing problems, but also relative increases across time in such problems, were related to more controlling parenting. These results are consistent with findings among typically developing populations and indicate that parents respond to 
aggressive and rule-breaking behavior by relying on external or internal pressure in order to change the behavior of their child (de Haan et al., 2013). Mediation analyses showed that this association was partially mediated through the frustration of parent's psychological needs. When youngsters with ASD exhibit aggressive or rule-breaking behavior, parents seem to feel like they have no control over their child's behavior and perceive this as an indication of parental incompetence. Furthermore, as parents might avoid certain situations or activities in order to prevent their child from exhibiting aggressive or rule-breaking behavior, parents might feel limited in their freedom (autonomy need frustration). Finally, these externalizing problems can impede the parents' relatedness with their child because it can create alienation, distrust or even fear in parents. In turn, the experience of need frustration can drain parents' energy, prompting them to respond in controlling ways (de Haan et al., 2013). In sum, this study is one of the first to identify parents' psychological needs as an important intervening mechanism in the association between externalizing child behavior and controlling parenting in a sample of adolescents and emerging adults with ASD.

Regarding perceived symptom severity, we found evidence for a direct association with autonomy support indicating that parents offer less choice, encourage initiative less, recognize the child's perspective or feelings less, and/or use meaningful rationales less often when their child exhibits more severe autism symptoms (at least as perceived by the parents). Again, the supplementary analyses showed that not only concurrent levels of symptoms but also relative increases in severity of autism symptoms were related to less autonomy-supportive parenting. Notably, this association is not mediated by need frustration, suggesting that there is something about these symptoms themselves which limits parents' possibilities to support autonomy. For instance, parents may feel like attempts to display empathy are not well understood by the child, who has difficulties interpreting emotion-related signals. As a consequence, they may decrease attempts to display empathy (i.e., a key feature of autonomy support as conceptualized in SDT). As symptom severity increases, parents may also be confronted with difficulties in supporting their child's need for autonomy and need for competence simultaneously. Adolescents with severe symptoms may require much more parental guidance and structure through schedules and routines. Although such a highly structured approach may meet the child's need for predictability and competence, it may set limits to autonomy supportive parenting. That is, a highly structured approach may hinder more autonomy-supportive parenting practices, such as encouraging initiative.

As this study is the first to demonstrate this direct relationship between parent-perceived severity of ASD symptoms and autonomy-supportive parenting, future research needs to examine why it is that parents offer less autonomy support when their child exhibits high symptom levels by employing, for instance, a qualitative study design. Further, the finding that symptom severity is unrelated to need frustration, suggests that parents might attribute autism symptoms as uncontrollable or unintentional by the child (Whittingham, Sofronoff, Sheffield, \& Sanders, 2008) which might protect them from feeling less competent or from feeling alienated from their child. To test these assumptions, future research could examine more in-depth the attribution processes involved in parental appraisals of ASD symptoms and problem behaviors. The finding that perceived symptom severity did not impact on parents' psychological needs might also be related to the age of the children with ASD in this study. As the children are all adolescents or emerging adults, their parents have had ample of time to learn how to interpret and deal with the specific autism symptoms. As such, they might take these symptoms less personally and be less inclined to evaluate their own competence and their connection with their child on the basis of the autism symptoms. Although the final model shows that symptom severity is unrelated to the overall score for need frustration, the correlations do indicate that autism symptoms are related specifically to parents' frustration of their need for autonomy. Parents might not perceive the autism symptoms as a threat to their competence nor as a threat to the attachment bond, however, certain symptoms might frustrate parents' volitional functioning. For instance, if a child becomes distressed because his/her daily routine changes, their parents might feel like their child's needs control their life.

Finally, in the current study, internalizing problems were not related to controlling or autonomy supportive parenting. This finding is consistent with findings of Dieleman et al. (2017) indicating limited evidence for the impact of internalizing problems on parenting in ASD. However, other studies in ASD groups (Greenberg et al., 2006) and in typically developing populations (Soenens, Luyckx, Vansteenkiste, Duriez, \& Goossens, 2008) do show that internalizing problems are associated with parenting behavior. The lack of associations between internalizing problems and parenting behavior in this study could indicate that there is a high level of variability in the way parents respond to these problem behaviors. An important aim for future research is to explore potential moderators of this relationship. Possibly, some parents respond to internalizing problems by becoming more controlling, whereas other parents might become increasingly supportive. Therefore, it might be particularly interesting to examine the moderating role of parental personality characteristics as research in typical development has identified that personality traits such as high neuroticism (Prinzie, Stams, Deković, Reijntjes, \& Belsky, 2009) increase the odds that parents' use maladaptive controlling strategies.

\subsection{Implications}

These findings yield more insight into the processes behind associations between problems co-occurring with ASD and parental behavior but also have several practical implications. The transition to adulthood can be very stressful for both youngsters with ASD and their parents. Interventions targeting probands with ASD and their parents in this challenging developmental period could focus not only on changing parenting behavior (which can be difficult given that parents have already built up a long history of interacting with their child by adolescence and emerging adulthood) but also on parents' experiences of need frustration. Interventions can raise awareness about the impact of child behavior on parents' psychological needs and about the importance of these needs for parenting behavior. By being aware of the role of psychological needs, parents might be more likely to resist their gut reaction to increase control when confronted with aggressive or rule-breaking behavior. As mindfulness and mindful parenting have been identified as mediators in the relationship between child behavior problems and maternal well-being, mindfulness-based interventions may be particularly effective to accomplish this goal (Jones, Hastings, Totsika, Keane, \& Rhule, 2014). Interventions could also include 
techniques to cope with need frustration or to discuss strategies to decrease need frustration (see Weinstein, Khabbaz, \& Legate, 2016).

\subsection{Limitations and future directions}

The generalizability of the present findings is limited by the specific choice of measures and by exclusively relying on a single informant, the parent (mainly mothers). Future research should try to circumvent the problem of shared method variance by relying on multiple informants including probands' appraisals of problems and parenting practices. In addition, it is important for future research to examine the generalization of the model tested in this study by including a more balanced sample of fathers and mothers and by including parents with more diverse ethnicities/nationalities. Additional research with fathers is much needed because fathers are known to participate substantially less often than mothers in research on ASD (Braunstein, Peniston, Perelman, \& Cassano, 2013). While research in the general population begins to suggest that the role of children's behavior (Aunola, Viljaranta, \& Tolvanen, 2017) and parents' needs-based experiences (Mabbe et al., in press) in parenting is largely similar in mothers and fathers, research has yet to demonstrate the generalization of these effects across parental gender in the context of ASD.

Also, this study had to rely on clinical judgment of ASD diagnoses and on parent appraisals of ASD symptom severity. Future work examining the impact of autism severity on parenting should include more objective assessments, such as the Autism Diagnostic Observation Schedule (Lord et al., 2012) for measuring symptom severity. Future research should also examine additional parenting dimensions as controlling and autonomy supportive parenting are only two of many important parenting practices. Dimensions such as expressed emotion, structure provision, or need-sensitivity are interesting candidates to evaluate as potential predictors in the development of youth with ASD.

Most importantly, the cross-sectional design prevents drawing conclusions about the direction of effects. It is feasible that parents' psychological needs do not only impact on parenting behavior, but that parenting might also affect parents' psychological needs (Deci, La Guardia, Moller, Scheiner, \& Ryan, 2006). Furthermore, parenting behavior will also relate to future child maladjustment. Thus, all included variables of the retrieved model may be bidirectionally related and these relationships can only be identified by multi-wave longitudinal research. Such research will also allow examining the degree to which changes in child behavior are related to changes in parental psychological needs experiences and parenting behavior. As such, longitudinal research is strongly needed to draw a more dynamic picture of the undoubtedly complex and bidirectional associations between the variables in our proposed model. Finally, future work should be undertaken to examine variables which buffer the relation between child maladjustment and parental need frustration. Our findings indicate that the relationship between child maladjustment and parental need frustration is not a perfect one, indicating that sometimes or for some parents, problem behavior and/or ASD symptoms do not relate to frustration of parents' psychological needs. Future research should address which parent characteristics (e.g., mindfulness, personality) or contextual factors (e.g., social support) prevent this translation into need frustration.

\section{Conclusion}

This study partially confirms the expected associations between child maladjustment (i.e., problem behavior and autism severity), parents' psychological needs, and parenting behavior. Only externalizing problems impact indirectly on controlling parenting, via parental need frustration, indicating that parents' psychological needs are an important underlying mechanism in this association. Perceived autism severity, however, is directly associated with less autonomy support.

\section{Acknowledgments}

This research was funded by grants from the Marguerite-Marie Delacroix Support Fund (GV/B-202) and the Fund for Scientific Research Flanders (FWO) (12B4614N and 11X6516N). The authors wish to thank all the participating families, the autism service centers and organizations that contributed to this research.

\section{References}

Abidin, R. R. (1990). Introduction to the special issue: The stresses of parenting. Journal of Clinical Psychology, 19, $298-301$.

Achenbach, T. M., \& Rescorla, L. A. (2001). Manual for the ASEBA school-age forms \& profiles. Burlington, VT: University of Vermont, Research Center for Children, Youth, \& Families.

Arnold, D. S., O'Leary, S. G., Wolff, L. S., \& Acker, M. M. (1993). The parenting scale: A measure of dysfunctional parenting in discipline situations. Psychological Assessments, 5, 137-144.

Aunola, K., Viljaranta, J., \& Tolvanen, A. (2017). Does daily distress make parents prone to using psychologically controlling parenting? International Journal of Behavioral Development, 41, 405-414.

Barber, B. K. (1996). Parental psychological control: Revisiting a neglected construct. Child Development, 67, 3296-3319.

Bartholomew, K. J., Ntoumanis, N., Ryan, R. M., Bosch, J. A., \& Thogersen-Ntoumani, C. (2011). Self-determination theory and diminished functioning: The role of interpersonal control and psychological need thwarting. Personality and Social Psychology Bulletin, 37, 1459-1473.

Beurkens, N. M., Hobson, J. A., \& Hobson, P. R. (2013). Autism severity and qualities of parent-child relations. Journal of Autism and Developmental Disorders, 43, 168-178.

Bollen, K. A. (1989). Structural equations with latent variables. New York: Wiley.

Braunstein, V. L., Peniston, N., Perelman, A., \& Cassano, M. C. (2013). The inclusion of fathers in investigations of autistic spectrum disorders. Research in Autism Spectrum Disorders, 7, 858-865.

Constantino, J. N., \& Gruber, C. (2005). Social responsiveness scale (SRS). Los Angeles, CA: Western Psychological Services. 
de Brock, A. J. L. L., Vermulst, A. A., Gerris, J. R. M., \& Abidin, R. R. (1992). NOSI, handleiding experimentele versie. Amsterdam: Pearson.

Deci, E. L., \& Ryan, R. M. (2000). The what and why of goal pursuits: Human needs and the self-determination of behavior. Psychological Inquiry, 11, 227-268.

de Haan, A. D., Soenens, B., Deković, M., \& Prinzie, P. (2013). Effects of childhood aggression on parenting during adolescence: The role of parental psychological need satisfaction. Journal of Clinical Child \& Adolescent Psychology, 42, 393-404.

Deci, E. L., La Guardia, J. G., Moller, A. C., Scheiner, M. J., \& Ryan, R. M. (2006). On the benefits of giving as well as receiving autonomy support: Mutuality in close friendships. Personality and Social Psychology Bulletin, 32, 313-327.

Dieleman, L. M., De Pauw, S. S. W., Soenens, B., Beyers, W., \& Prinzie, P. (2017). Examining bidirectional relationships between parenting and child maladjustment in youth with autism spectrum disorder: A nine-year longitudinal study. Development and Psychopathology, 29, 1199-1213.

Gilmore, L., Cuskelly, M., Jobling, A., \& Hayes, A. (2009). Maternal support for autonomy: Relationships with persistence for children with Down syndrome and typically developing children. Research in Developmental Disabilities, 30, 1023-1033.

Greenberg, J. S., Seltzer, M. M., Hong, J., \& Orsmond, G. I. (2006). Bidirectional effects of expressed emotion and behavior problems and symptoms in adolescents and adults with autism. American Journal on Mental Retardation, 111, 229-249.

Grolnick, W. S., Ryan, R. M., \& Deci, E. L. (1991). Inner resources for school-achievement-Motivational mediators of childrens perceptions of their parents. Journal of Educational Psychology, 83, 508-517.

Grolnick, W. S., Gurland, S. T., DeCourcey, W., \& Jacob, K. (2002). Antecedents and consequences of mothers' autonomy support: An experimental investigation. Developmental Psychology, 38, 143-155.

Grolnick, W. S. (2003). The psychology of parental control: How well-meant parenting backfires. Mahwah, NJ: Erlbaum.

Hayes, S. A., \& Watson, S. L. (2013). The impact of parenting stress: A meta-analysis of studies comparing the experience of parenting stress in parents of children with and without autism spectrum disorder. Journal of Autism and Developmental Disorders, 43, 629-642.

Hobson, J. A., Tarver, L., Beurkens, N., \& Hobson, R. P. (2016). The relation between severity of autism and caregiver-child interaction: A study in the context of relationship development intervention. Journal of Abnormal Child Psychology, 44, 745-755.

Hoffman, C. D., Sweeney, D. P., Hodge, D., Lopez-Wagner, M. C., \& Looney, L. (2009). Parenting stress and closeness: Mothers of typically developing children and mothers of children with autism. Focus on Autism and Other Developmental Disabilities, 24, 178-187.

Holmbeck, G. N. (1997). Toward terminological, conceptual, and statistical clarity in the study of mediators and moderators: Examples from the child-clinical and pediatric psychology literatures. Journal of Consulting and Clinical Psychology, 65, 599-610.

Holtmann, M., Bolte, S., \& Poustka, F. (2007). Autism spectrum disorders: Sex differences in autistic behaviour domains and coexisting psychopathology. Developmental Medicine and Child Neurology, 49, 361-366.

Hu, L., \& Bentler, P. M. (1999). Cutoff criteria for fit indexes in coviarance structure analysis: Conventional criteria versus new alternatives. Structural Equation Modeling- A Multidisciplinary Journal, 6, 1-55.

Jones, L., Hastings, R. P., Totsika, V., Keane, L., \& Rhule, N. (2014). Child behavior problems and parental well-being in families of children with autism: The mediating role of mindfulness and acceptance. American Journal on Intellectual and Developmental Disabilities, 119, 171-185.

Joussemet, M., Landry, R., \& Koestner, R. (2008). A self-determination theory perspective on parenting. Canadian Psychology, 49, 194-200.

Kline, R. B. (2010). Principles and practice of structural equation modelin (3th ed.). The Guilford Pess.

Little, T. D., Cunningham, W. A., Shahar, G., \& Widaman, K. F. (2002). To parcel or not to parcel: Exploring the question, weighing the merits. Structural Equation Modeling, 9, 151-173.

Lord, C., Rutter, M., DiLavore, P. C., Risi, S., Gotham, K., \& Bishop, S. (2012). Autism diagnostic observation schedule (2nd ed.). Torrance, CA: Western Psychological Services.

Mabbe, E., Soenens, B., Vansteenkiste, M., Van der Kaap-Deeder, J., \& Mouratidis, T. (in press). Day-to-day variation in autonomy-supportive and psychologically controlling parenting: The role of parents' daily experiences of need satisfaction and need frustration. Parenting: Science and Practice.

Muthén, L. K., \& Muthén, B. O. (1998-2012). Mplus user's guide. 7th ed. Los Angeles, CA: Muthén \& Muthén.

Nelson, L. J., Padilla-Walker, L. M., Christensen, K. J., Evans, C. A., \& Carroll, J. S. (2011). Parenting in emerging adulthood: An examination of parenting clusters and correlates. Journal of Youth and Adolescence, 40, 730-743.

Osborne, L. A., \& Reed, P. (2009). The relationship between parenting stress and behavior problems of children with autistic spectrum disorders. Exceptional Children, 76, 54-73.

Preacher, K. J., \& Hayes, A. F. (2008). Asymptotic and resampling strategies for assessing and comparing indirect effects in multiple mediator models. Behavior Research Methods, 40, 879-891.

Prinzie, P., Onghena, P., \& Hellinckx, W. (2007). Re-examining the Parenting Scale. Reliability, factor structure, and concurrent validity of a scale for assessing the discipline practices of mothers and fathers of elementary-school-aged children. European Journal of Psychological Assessment, $23,24-31$.

Prinzie, P., Stams, G. J., Deković, M., Reijntjes, A. H., \& Belsky, J. (2009). The relations between parents' Big Five personality factors and parenting: A meta-analytic review. Journal of Personality And Social Psychology, 97, 351-362.

Reutebuch, C. K., El Zein, F., \& Roberts, G. J. (2015). A systematic review of the effects of choice on academic outcomes for students with autism spectrum disorder. Research in Autism Spectrum Disorder, 20, 1-16.

Rodrigue, J. R., Morgan, S. B., \& Geffken, G. (1990). Families of autistic children: Psychological functioning of mothers. Journal of Clinical Child Psychology, 19, $371-379$.

Roeyers, H., Thys, M., Druart, C., De Schryver, M., \& Schittekatte, M. (2011). Handleiding Screeningslijst voor autismespectrumstoornissen. Amsterdam: Hogrefe Uitgevers B.V.

Seltzer, M. M., Krauss, M. W., Orsmond, G. I., \& Vestal, C. (2001). Families of adolescents and adults with autism: Uncharted territory. In L. M. Glidden (Ed.). International review of research on mental retardation (pp. 267-294). San Diego: Academic Press.

Shea, N. M., Millea, M. A., \& Diehl, J. J. (2013). Perceived autonomy support in children with autism spectrum disorder. Autism-Open Access, 3.

Smith, L. E., Greenberg, J. S., Seltzer, M. M., \& Hong, J. (2008). Symptoms and behavior problems of adolescents and adults with autism: Effects of mother-child relationship quality, warmth, and praise. American Journal of Mental Retardation, 113, 387-402.

Soenens, B., \& Vansteenkiste, M. (2010). A theoretical upgrade of the concept of parental psychological control: Proposing new insights on the basis of self-determination theory. Developmental Review, 30, 74-99.

Soenens, B., Vansteenkiste, M., Luyckx, K., \& Goossens, L. (2006). Parenting and adolescent problem behaviors: An integrated model with adolescent self-disclosure and perceived parental knowledge as intervening variables. Developmental Psychology, 42, 305-318.

Soenens, B., Luyckx, K., Vansteenkiste, M., Duriez, B., \& Goossens, L. (2008). Clarifying the link between parental psychological control and adolescents' depressive symptoms reciprocal versus unidirectional models. Merrill-Palmer Quarterly-Journal Of Developmental Psychology, 54, $411-444$.

Taylor, J. L., \& Seltzer, M. M. (2010). Changes in the autism behavioral phenotype during the transition to adulthood. Journal of Autism and Developmental Disorders, 40, $1431-1446$.

Taylor, J. L., \& Seltzer, M. M. (2011). Changes in the mother-child relationship during the transition to adulthood for youth with autism spectrum disorders. Journal of Autism and Developmental Disorders, 41, 1397-1410.

Weinstein, N., Khabbaz, F., \& Legate, N. (2016). Enhancing need satisfaction to reduce psychological distress in Syrian refugees. Journal of Consulting and Clinical Psychology, 84, 645-650.

Whittingham, K., Sofronoff, K., Sheffield, J., \& Sanders, M. R. (2008). An exploration of parental attributions within the autism spectrum disorders population. Behavioral Change, 25, 201-214. 